\title{
Application of Corpus Technology in British and American Literature Course Teaching \\ Ping Chen
}

Ankang University,Ankang,725000,China

\begin{abstract}
Keywords: Corpus Technology, British and American Literature, Teaching
\end{abstract}
\begin{abstract}
As a specialized course of improving the humanistic quality and language basic skills of college students majoring in languages, British and American literature teaching faces problems of improving teaching methods all the way. Some researches have proved that building and using of corpus is an important way of improving British and American literature teaching quality. This paper elaborates the definition of corpus, analyzes the construction principle of corpus technology in British and American literature courses, discusses the application methods of corpus technology in British and American literature teaching, and puts forward the problems of corpus technology that need attention in British and American literature teaching application.
\end{abstract}

\section{Introduction}

Corpus technology, which takes discourse as its basis, is one of the disciplines of understanding certain language culture and conducting researches. Corpus is able to collect and organize systematically numerous linguistic and cultural materials. These materials without processing are the basic materials for linguistic statistics and are able to be applied to multiple aspects like literary work study, lexicographical work, literature teaching, etc. In the past, corpus materials are mainly collected by people. Nowadays, the efficiency and scale of corpus building have been greatly improved by using advanced computer technology, which sets good foundation for corpus building and application. Its position in British and American literature teaching field has been especially promoted.

\section{Definition of corpus}

Corpus, as a kind of text collection applied to linguistic analysis, has representativeness for a certain language or dialect. It is the collection of natural languages that have been stored in computers, reflecting the language state and changing characteristics. In terms of categories, corpus can be divided into general corpus and specialized corpus. The former mainly explores languages' universal rules like lexicographical work, grammar study, etc; while the latter discusses a certain field or a certain goal like spoken corpus, medical English vocabulary corpus, etc. The expression forms of corpus languages are various. They can be corpus of either text type or image data type or mixed type. In light of the rapid development of corpus linguistics, corpus development also shows the following features: firstly, the building and researches of learners' corpus have become the key points of corpus linguistics researches; secondly, researches on the spoken corpus building and related discourse characteristics are constantly increasing; thirdly, effects of parallel corpus in language comparison and translation are continuously reinforced; fourthly, corpus building researches become more and more universal; fifthly, corpus researches are developed in depth.

\section{Building principle of corpus technology in British and American literature course}

Firstly, it emphasizes the nature, contents, goal and principle of British and American literature course. Teaching of British and American literature course covers fairly wide areas. There are many types of textbooks with different complexities, referring to the historical background at that time, author's life experience, main writing style, excerpts of representative works, etc. Therefore, above contents should be fully taken into consideration when building British and American literature course corpus. At the same time, teaching characteristics, hierarchy and systematicness should all be 
emphasized.

Secondly, building British and American literature course corpus should reinforce learners' requirement rules. According to corpus building goals, British and American literature teaching corpus should fully consider learners' reality and specific receptivity, meet the study demands of learners at different levels as much as possible, and provide hierarchical corpora resources with wide sources and case analysis application. As for undergraduates majoring in languages, British and American literature course takes a considerable proportion in postgraduate qualifying examination. There are so many intermingled good and bad reviewing materials on the market, and classroom teaching is sometimes disjointed with the colleges and universities which students have signed up for an examination. It causes numerous difficulties for reviewing and examination. Therefore, in process of building a corpus, knowledge centralization and systematization can be realized in accordance with some learners' actual demands. Putting the contents not involved in courses into corpus will meet college students' actual demands. At the same time, there will be data deficient problems when college students are writing British and American literature thesis. Therefore, essential network linking and booklist can also be provided in the process of active corpus building so that the most valuable information can be achieved in the shortest time.

Thirdly, it pays attention to the scientific and diversified principle of information source. In view of the numerous and jumbled corpus information, the accuracy and authority of selected information source should be ensured in building process in order to avoid misleading learners and causing counter-productive effects. At the same time, the teaching materials of British and American literature course are mainly text contents. We should improve the diversity of corpus by offering not only text data but also essential image data for learners while building. The constructivism theory actively advocates that learners use learning materials to build knowledge system through situation, context and also social background. Image data can not only help learners deepen the impression of knowledge they have learned but also expand the teaching contents which contain historical background introduction, text content elaboration, etc. Here we take a fiction work named The Portrait of a Lady of Henry James as an example to elaborate. In the corpus of this novel, the film named "The Portrait of a Lady" adapted from the novel can be linked in order to help learners understand the theme of this novel from different perspectives like sound, speech, image, etc. Indeed, the historical background possessed by literature development can also be supplemented by corresponding pictures. For example, elaborating video with social background or pictures in the process of explaining realism is able to help students deepen their understanding of works' historical background.

Fourthly, it lays emphasis on strengthening the cultivation of learners' critical thinking skills. The teaching objective of British and American literature course is to use classical text reading experience and elaboration to increase learners' life experience, enrich their cross-culture knowledge learning, cultivate their aesthetic judgment, and improve their language ability and thinking expression ability. However, in actual teaching, British and American literature teachers mostly lean to explanation of literary history knowledge while usually neglecting a significant teaching link namely students' personal reading experience. It will cause loss of aesthetic experience and make the cultivation of thinking ability an empty talk. Therefore, according to specific literature text, we should provide the learners with textual analysis cases that can be used for reference in British and American literature corpus building process, set related topic for classroom discussion or extracurricular thinking, make students able to put forward different evaluation perspectives for a same topic, make the best of students' experiential reading, carry out evaluation and recreation for works, and comprehensively promote learners' critical thinking skills.

\section{Application methods of corpus technology in British and American literature teaching}

At the initial stage of building British and American literature corpus, we should simply use all kinds of resources to collect cultural background and literature knowledge needed by British and American literature teaching. In addition, we should track the corpus, constantly supplement and perfect it, and gradually form a comparatively complete corpus system. Step one is to collecting all 
kinds of resources like image, sound, picture, text, etc and electronic teaching plans of British and American literature teachers. It will carry out organization and design according to knowledge points, and form more integrated literature topic in accordance with corresponding learning topics, including the CD of famous brands like Hongen Multimedia Classes, 1000 classics of Fudan University version, 3000 British and American classics of Peking University version, etc and also electronic courseware made by professional teachers. Step two is to make use of network advantages and create hyperlinks covering literature background and literary review in process of corpus building. Taking Shakespeare's works as an example, the corpus should provide film and television editing that can reflect works' linguistic features. It should also specially introduce related websites for comments on Shakespeare's works and background note and link them with other websites. Step three is to fully make use of functional software with computer analysis synthesis and searching. The common software mainly contains Microconcord, Wordsmith, Wconcord, etc. Therefore, we should use all kinds of resources to collect cultural background knowledge necessary in British and American literature teaching, set up corpus tracking, build more comprehensive corpus system in process of building British and American literature corpus. Consequently, the British and American literature teachers are able to generally and deeply grasp students' learning characteristics and overall perspective. In this way, problems that British and American literature teachers' teaching is lack of pertinence, students are at loose end, etc can be radically solved. Similarly, students' learning initiative can be improved.

In British and American literature corpus, there are advantages like computer logicality, pattern, etc in addition to diversified literature knowledge and cultural background. Therefore, British and American literature corpus plays a more and more irreplaceable role in literary education. Firstly, using British and American literature corpus is able to research and analyze a typical British and American literature pattern. Even though there is no lack of innovation in British and American literature, it is also equipped with typical patterns. Secondly, using British and American literature corpus is able to carry out literary researches especially on writers' writing style. Computer's unique technologies like searching, statistics, etc can be used to accurately count the word frequency, word length and sentence length in writers' works, and reflect writers' writing style and cultural background of a certain period. Thirdly, British and American literature teaching should be strengthened. An important goal of building British and American literature corpus is to consolidate British and American literature teaching. The application of corpus technology has more advantages, higher capacity, stronger choosability, more highlighted emphases and more distinct hierarchy than traditional teaching. It can scientifically reflect teaching effects.

\section{Problems of corpus technology that need attention in British and American literature teaching application}

In order to further explore corpus technology origin, future development tendency, and its application trend in British and American literature teaching, we should pay high attention to the latest literature report about corpus technology and British and American literature teaching at home and abroad. We should further research computer technologies. The rapid development of software development field has provided brand new forms for corpus technology building including new input, labeling and researching methods and new language data segmentation and statistics procedure. We should pay high attention to the latest development of corpus technology at home and abroad especially the developing status of specialized corpus technology in order to find out whether there are new experience and procedures able to be taken as reference. At the same time, the characteristics, advantages and disadvantages of the most popular corpus technology building framework software in linguistic field should also be studied. On basis of it, we can make auxiliary software more suitable for actual demands and target demands, further make specialized British and American literature corpus software with characteristics, and provide all kinds of resources needed by more scientific and reliable searching with sound technical support. In the meantime, we should carefully explore the main contents positioning of British and American literature and how to integrate labeling pattern symbols. That is to say, should we use Chinese terminology or English 
standard abbreviations symbols to label? In addition, we should study British and American literature history and developing changes, discuss related national departments' newest normative requirement for corpus, build more scientific, reliable and convenient British and American literature corpus which can be applied to corpus linguistics, computer technology and principle of statistics, and provide strong technology support for language teaching.

Indeed, when building and using corpus in British and American literature teaching, teachers and technicians should make great efforts to the following tasks: task one is to use computer technology to summarize the literary pattern or writers' style of typical significance. Plenty of electronic edition British and American literature corpus contain image, sound, picture and text. The integration of these materials is able to improve college students' learning initiative and is also able to be used in computer corpus to improve the systematicness of British and American literature teaching. Task two is to collect learners' information with corpus so that genuine teaching effects can be achieved. We should carry out both horizontal analysis and vertical analysis on feedback information in order to comprehensively grasp learners' situation and further strengthen pertinence of British and American literature teaching. Task three is to work out introductions for hardware and software. Hardware and software resources should be accurately described in accordance with systemic requirement and be synthesized to make British and American literature computer corpus convenient for teaching.

\section{Conclusion}

To sum up, the application of corpus technology in British and American literature teaching is still at the initial stage. It has many disadvantages and hasn't been paid high attention to by higher education workers. It lies in not only the facts that there are still no large-scale British and American literature language corpus in China and no existing corpus able to be applied to British and American literature teaching but also the fact that teachers and students aren't accustomed to teaching with corpus technology in a short while. However, corpus technology as a significant means of reinforcing British and American literature teaching will definitely bring British and American literature teaching brand new teaching methods. Educational workers in colleges and universities should deeply explore the feasibility of corpus technology in actual teaching, check it in further practice and promote the strengthening and perfecting of British and American literature course teaching system in China.

\section{References:}

[1]Li Wenliang. Analysis on British and American Literature Corpus Building and Its Application Value[J]. Journal of Tangshan Teachers College, 2009 (4).

[2]Wang Yanwen. Research on “Three Sources” Corpus Building of British and American Literature, Culture and Context[J]. Modern Educational Technology, 2010 (11).

[3]Zhang Chao. Multi-dimensional Analysis on Literary Works in Corpus View[J]. Journal of Mudanjiang University, 2012 (3) .

[4]Cai Huayan. Corpus Application in British and American Literature Teaching---Analysis on Language Features of The Adventures of Huckleberry[J].Journal of Tongling Vocational and Technical College, 2013 (2).

[5]Shi Xiuchuan. Corpus Application in Foreign Literature Researches [J]. Jiannan Literature, 2013 (8). 